\title{
Attitudes of healthcare workers in U.S. hospitals regarding
} smallpox vaccination

\author{
W Katherine Yih*1, Tracy A Lieu $1,2,3$, Virginia H Rêgo ${ }^{1}$, Megan A O'Brien ${ }^{1}$, \\ David K Shay ${ }^{4}$, Deborah S Yokoe ${ }^{5,6}$ and Richard Platt ${ }^{1,5,6,7}$
}

\begin{abstract}
Address: ${ }^{1}$ Department of Ambulatory Care and Prevention, Harvard Medical School and Harvard Pilgrim Health Care, Boston, MA, USA, ${ }^{2}$ Center for Child Health Care Studies, Harvard Pilgrim Health Care, Boston, MA, USA, 3Division of General Pediatrics, Children's Hospital Boston, USA, ${ }^{4}$ Immunization Safety Branch, National Immunization Program, Centers for Disease Control and Prevention, Atlanta, GA, USA, ${ }^{5} \mathrm{Channing}$ Laboratory, Department of Medicine, Brigham and Women's Hospital, Harvard Medical School, Boston, MA, USA, ${ }^{6}$ CDC Eastern Massachusetts Prevention Epicenter, USA and ${ }^{7} \mathrm{HMO}$ Research Network Center for Education and Research in Therapeutics, USA
\end{abstract}

Email: W Katherine Yih* - katherine_yih@harvardpilgrim.org; Tracy A Lieu - tracy_lieu@ harvardpilgrim.org;

Virginia H Rêgo - virginia_rego@harvardpilgrim.org; Megan A O'Brien - megan_obrien@harvardpilgrim.org; David K Shay - dks4@cdc.gov; Deborah S Yokoe - pedsy@channing.harvard.edu; Richard Platt - perip@channing.harvard.edu

* Corresponding author

Published: II June 2003

BMC Public Health 2003, 3:20
Received: 13 March 2003

Accepted: II June 2003

This article is available from: http://www.biomedcentral.com/I47/-2458/3/20

(C) 2003 Yih et al; licensee BioMed Central Ltd. This is an Open Access article: verbatim copying and redistribution of this article are permitted in all media for any purpose, provided this notice is preserved along with the article's original URL.

\begin{abstract}
Background: The United States is implementing plans to immunize 500,000 hospital-based healthcare workers against smallpox. Vaccination is voluntary, and it is unknown what factors drive vaccine acceptance. This study's aims were to estimate the proportion of workers willing to accept vaccination and to identify factors likely to influence their decisions.
\end{abstract}

Methods: The survey was conducted among physicians, nurses, and others working primarily in emergency departments or intensive care units at 21 acute-care hospitals in 10 states during the two weeks before the U.S. national immunization program for healthcare workers was announced in December 2002. Of the questionnaires distributed, I, I65 were returned, for a response rate of $81 \%$. The data were analyzed by logistic regression and were adjusted for clustering within hospital and for different number of responses per hospital, using generalized linear mixed models and SAS's NLMIXED procedure.

Results: Sixty-one percent of respondents said they would definitely or probably be vaccinated, while $39 \%$ were undecided or inclined against it. Fifty-three percent rated the risk of a bioterrorist attack using smallpox in the United States in the next two years as either intermediate or high. Forty-seven percent did not feel well-informed about the risks and benefits of vaccination. Principal concerns were adverse reactions and the risk of transmitting vaccinia. In multivariate analysis, four variables were associated with willingness to be vaccinated: perceived risk of an attack, selfassessed knowledge about smallpox vaccination, self-assessed previous smallpox vaccination status, and gender.

Conclusions: The success of smallpox vaccination efforts will ultimately depend on the relative weight in people's minds of the risk of vaccine adverse events compared with the risk of being exposed to the disease. Although more than half of the respondents thought the likelihood of a bioterrorist smallpox attack was intermediate or high, less than $10 \%$ of the group slated for vaccination has actually accepted it at this time. Unless new information about the threat of a 
smallpox attack becomes available, healthcare workers' perceptions of the vaccine's risks will likely continue to drive their ongoing decisions about smallpox vaccination.

\section{Background}

The United States began to implement a national plan to immunize half a million hospital-based healthcare workers against smallpox in early 2003. Prospective vaccinees are healthcare workers in emergency departments, intensive care units, and other settings who would be crucial first-line responders in the event of a bioterrorist attack using smallpox. However, vaccination is voluntary, and many staff members are declining. In Israel, almost half of healthcare workers and security and rescue squad personnel refused voluntary smallpox vaccination in 2002 due to concerns about vaccine adverse events, according to one press report [1].

In early December 2002, just before the current smallpox vaccination plan was announced, we carried out a survey of U.S. healthcare workers' opinions about smallpox vaccination in order to inform preparedness efforts. Although much has happened to change public opinion since that time, our findings provide insight into factors that influence the ongoing decision-making of healthcare workers about this vaccine.

\section{Methods \\ Study Sample}

We surveyed a convenience sample of healthcare workers at 21 (of 22 invited) acute-care hospitals in 10 states between December 2 and 18, 2002 to determine their knowledge, attitudes, and projected behavior regarding smallpox vaccination. All but one of the hospitals were members of the Prevention Epicenters established by the Centers for Disease Control and Prevention (CDC) or the Duke Infection Control Outreach Network (DICON). The hospitals were located in Massachusetts (8), North Carolina (3), Maryland (2), Virginia (2), and Georgia, New York, Missouri, Illinois, Iowa and Oregon (1 each). The population of interest for the survey was emergency department (ED) and intensive care unit (ICU) staff, although surveys were also completed by limited numbers of other staff (e.g. radiology technicians) who might plausibly be involved in a smallpox admission. Of the 1,443 surveys distributed to staff, 1,165 were completed within the required time-frame, for a response rate of $81 \%$.

\section{Procedures}

The hospital epidemiologists or infection control practitioners obtained institutional review board (IRB) approval (or, in some cases, exemption from review) and administered the survey to their hospital's ED and ICU staff. Collaborators agreed to return a minimum of 25 completed surveys to the study investigators by December 20, 2002.

The self-administered survey was anonymous, confidential, and voluntary. It was distributed during staff meetings or in person on an individual basis, or occasionally via mailboxes. A draft smallpox vaccine information sheet (CDC's 11/20/2002 version, see Additional File 1) was placed inside each folded questionnaire. The draft information sheet did not include photographs of adverse reactions, nor did it describe the inflammatory response at immunization site that occurs among a substantial fraction of individuals. At 16 of the 21 hospitals, a good-quality pen was handed out with each survey; at another, small gift certificates were used; the remaining 4 hospitals did not employ gifts. The completed surveys were collected at each site by the collaborator, who also tracked the total number of surveys that had been distributed.

\section{Survey instrument}

The questionnaire (see Additional File 2) consisted of 17 multiple-choice questions, mostly about respondents' attitudes and projected behavior regarding smallpox and smallpox vaccination, knowledge and topics of concern, and self-assessed health history relative to smallpox vaccination (previous vaccination, contraindications). A number of questions addressed demographic and occupational characteristics. A question at the end of the survey asked how carefully respondents had read the enclosed vaccine information sheet.

\section{Analysis}

The main outcome variable was respondents' expressed willingness to accept vaccination, which was dichotomized as yes/probably vs. no/probably not/don't know and then correlated with potential predictors of response, individually and by multivariate logistic regression. The variables initially included in the model were perceived risk of a smallpox attack, region, main work area, profession, age, gender, presence or absence of children $\leq 18$ years old at home, self-assessed previous vaccination status, self-assessed level of knowledge about smallpox vaccination, and how well one had read the vaccine information sheet. This list includes all the questions on the questionnaire except those addressing: reasoning underlying one's attitude toward vaccination, contraindications, and projected behavior under hypothetical scenarios. These excluded variables were considered irrelevant as predictors or were intractable for inclusion due to the structure of the corresponding questions; 
Table I: Healthcare workers' characteristics and self-reported willingness to accept smallpox immunization

\begin{tabular}{|c|c|c|c|c|c|c|c|}
\hline & \multicolumn{2}{|c|}{ Total } & \multicolumn{5}{|c|}{ By expressed willingness to be immunized } \\
\hline & \multirow[b]{2}{*}{$\mathrm{n}$} & \multirow[b]{2}{*}{$\%$} & \multicolumn{2}{|c|}{ Yes/probably } & \multicolumn{2}{|c|}{$\begin{array}{l}\text { Probably not/no/ } \\
\text { don't know }\end{array}$} & \multirow[b]{2}{*}{ p-value* } \\
\hline & & & $\mathrm{n}$ & $\%$ & $\mathrm{n}$ & $\%$ & \\
\hline All & 1165 & $100 \%$ & 708 & $61 \%$ & 450 & $39 \%$ & \\
\hline Perceived risk of attack & & & & & & & $<0.0001$ \\
\hline High/intermediate & 610 & $53 \%$ & 422 & $70 \%$ & 184 & $30 \%$ & \\
\hline Low/next to zero & 400 & $35 \%$ & 185 & $47 \%$ & 212 & $53 \%$ & \\
\hline Can't guess & 144 & $12 \%$ & 95 & $66 \%$ & 49 & $34 \%$ & \\
\hline Region & & & & & & & 0.03 \\
\hline Northeast (9 hospitals) & 503 & $43 \%$ & 278 & $56 \%$ & 222 & $44 \%$ & \\
\hline Mid-Atlantic \& Southeast (8 hospitals) & 317 & $27 \%$ & 205 & $65 \%$ & 111 & $35 \%$ & \\
\hline Midwest \& West (4 hospitals) & 345 & $30 \%$ & 225 & $66 \%$ & 117 & $34 \%$ & \\
\hline Main work area & & & & & & & 0.11 \\
\hline ED or ED consult & 558 & $48 \%$ & 349 & $63 \%$ & 208 & $37 \%$ & \\
\hline ICU (adult or pediatric) or consult & 434 & $37 \%$ & 248 & $57 \%$ & 184 & $43 \%$ & \\
\hline Other/none specified & 173 & $15 \%$ & 111 & $66 \%$ & 58 & $34 \%$ & \\
\hline Profession & & & & & & & 0.86 \\
\hline Physician & 351 & $30 \%$ & 210 & $61 \%$ & 137 & $39 \%$ & \\
\hline Non-physician clinician & 642 & $55 \%$ & 392 & $61 \%$ & 248 & $39 \%$ & \\
\hline Other/none specified & 172 & $15 \%$ & 106 & $62 \%$ & 65 & $38 \%$ & \\
\hline Age & & & & & & & 0.41 \\
\hline Up to 29 & 277 & $24 \%$ & 170 & $62 \%$ & 106 & $38 \%$ & \\
\hline $30-39$ & 356 & $31 \%$ & 206 & $58 \%$ & 147 & $42 \%$ & \\
\hline $40-49$ & 315 & $27 \%$ & 191 & $61 \%$ & 121 & $39 \%$ & \\
\hline 50 or over & 207 & $18 \%$ & 135 & $65 \%$ & 72 & $35 \%$ & \\
\hline Gender & & & & & & & $<0.0001$ \\
\hline Male & 408 & $35 \%$ & 257 & $63 \%$ & 148 & $37 \%$ & \\
\hline Female & 743 & $65 \%$ & 440 & $60 \%$ & 299 & $40 \%$ & \\
\hline Children $<18$ at home? $* *$ & & & & & & & $<0.000 I^{* *}$ \\
\hline Yes & 461 & $41 \%$ & 281 & $61 \%$ & 177 & $39 \%$ & \\
\hline No & 676 & $59 \%$ & 413 & $61 \%$ & 259 & $39 \%$ & \\
\hline Ever vaccinated against smallpox & & & & & & & 0.07 \\
\hline Yes & 606 & $52 \%$ & 384 & $64 \%$ & 217 & $36 \%$ & \\
\hline No & 418 & $36 \%$ & 241 & $58 \%$ & 175 & $42 \%$ & \\
\hline Not sure & 140 & $12 \%$ & 82 & $59 \%$ & 58 & $41 \%$ & \\
\hline $\begin{array}{l}\text { How well informed about risks and benefits } \\
\text { of smallpox vaccination }\end{array}$ & & & & & & & 0.0002 \\
\hline Very well & 138 & $12 \%$ & 98 & $72 \%$ & 39 & $28 \%$ & \\
\hline Fairly well & 474 & $41 \%$ & 304 & $65 \%$ & 167 & $35 \%$ & \\
\hline Not well & 456 & $39 \%$ & 255 & $56 \%$ & 198 & $44 \%$ & \\
\hline Not at all & 94 & $8 \%$ & 50 & $53 \%$ & 44 & $47 \%$ & \\
\hline $\begin{array}{l}\text { How carefully read accompanying smallpox } \\
\text { vaccine information sheet** }\end{array}$ & & & & & & & $<0.000 I^{* *}$ \\
\hline Read carefully & 534 & $47 \%$ & 326 & $62 \%$ & 204 & $38 \%$ & \\
\hline Read some parts & 182 & $16 \%$ & 111 & $62 \%$ & 69 & $38 \%$ & \\
\hline Skimmed quickly & 234 & $21 \%$ & 150 & $64 \%$ & 84 & $36 \%$ & \\
\hline Didn't read it & 189 & $17 \%$ & 106 & $56 \%$ & 83 & $44 \%$ & \\
\hline
\end{tabular}

NB: Where subtotals do not add to 1,165 , this is due to missing answers on the questionnaire. * Adjusted for clustering within hospital and variation in the number of responses per hospital. ** Two variables, children at home and reading the VIS, were statistically significant in the bivariate analysis but were excluded from the multivariate model. Hospital-specific odds ratios for favoring vaccination with children at home compared to without children at home ranged from 0.22 to 5.5 , but only one of the 21 was statistically significant (OR I.I4, $p=.03$ ). Similarly, on hospital-specific analysis, odds ratios for the various levels of reading the VIS compared to not reading it at all varied from 0.09 (for reading parts of it) to 5.3 (for reading it carefully) and none were statistically significant. We concluded that there was little evidence of a meaningful association and removed both variables from the final multivariate model. 
overall results on them are presented in univariate form without weighting or other adjustment. All p-values and estimates from the logistic regression analysis (and presented in the tables) are adjusted for clustering within hospital and for different number of responses per hospital, using generalized linear mixed models [2]. The data were analyzed in SAS using the NLMIXED procedure. A fuller description of the analysis is available on request.

\section{Results}

\section{Characteristics of the hospitals and respondents}

Seventeen of the 21 hospitals were in the Northeast and Mid-Atlantic/Southeast (Table 1). Eleven were tertiarycare centers, with $69 \%$ of the respondents; 9 were community hospitals, with $27 \%$ of the respondents; and one was a Veterans Administration hospital, with $4 \%$. The median number of beds was 427, with a range of 113 to 1,442 . Approximately half of respondents worked in the ED (or provided consultation to it), approximately half were nurses, and approximately two-thirds were women (Table $1)$.

\section{Perceptions of smallpox threat and vaccine risks}

Fifty-three percent of respondents thought the risk of a smallpox attack in the U.S. within the next two years was either "intermediate" (38\%) or "high" (15\%), while 35\% saw it as either "low" (29\%) or "next to zero" (6\%), and $12 \%$ said "can't guess." Opinions varied widely among the various hospitals, with a range of $27 \%$ to $73 \%$ per hospital considering the risk of an attack to be intermediate or high $(\mathrm{p}<.02$, chi-square test on crude data).

Twelve percent of respondents felt they were "very well informed" about smallpox vaccination, $41 \%$ felt "fairly well informed," 39\% said "not well informed," and 8\% answered "not at all informed" (Table 1). The topics about which information was most commonly desired were (1) the likelihood and nature of adverse events $(28 \%$ of the answers chosen), (2) the risks and health problems of transmitting vaccinia to others (15\% of the answers), and (3) the risk of a smallpox attack (15\%) (Table 2). The most frequently chosen top concern about vaccination was the risks compared to the benefits of vaccination (53\%), followed by the risks of transmitting vaccinia to family or friends $(26 \%)$. Of the different types of adverse events, $70 \%$ of respondents were most concerned about severe reactions like encephalitis, severe infection, and death; while $18 \%$ were more concerned about the more frequent mild-to-moderate reactions, and $11 \%$ said they were not particularly worried about vaccine adverse events.

When asked at the end of the survey how carefully they had read the accompanying vaccine information sheet, $47 \%$ of respondents said they had read it carefully, $16 \%$ said they had read parts of it, $21 \%$ reported skimming it quickly, and 17\% said they hadn't read it (Table 1). Attention to the vaccine information sheet appeared to be associated with one's top concern ( $\mathrm{p}=.035$, chi-square test on crude data), with, for example, $30 \%$ of those reporting having carefully read it listing transmission of vaccinia to family or friends as their principal concern, compared to $17 \%-26 \%$ of the groups reading the vaccine information sheet less carefully or not at all.

\section{Self-assessed health history relative to smallpox vaccination}

Fifty-two percent of respondents reported having been previously vaccinated against smallpox, $36 \%$ said they had not, while $12 \%$ weren't sure. Of those $<30$ years of age, $11 \%$ reported having been vaccinated; of those $\geq 30$, $23 \%$ reported not having been vaccinated (Table 2 ). Six percent reported having a child or children $<1$ year of age at home, currently a "precaution" rather than a contraindication to smallpox vaccination. Forty-five percent of those who completed the question on contraindications said either "yes" (37\%) or "don't know" (8\%) to at least one of the contraindications in our list of 8 . The most common (self-reported) contraindication was household member with current or past history of eczema or atopic dermatitis $-16 \%$ of respondents reported this situation. The next most frequent contraindication was current or past history of eczema or atopic dermatitis in oneself, reported by $13 \%$.

\section{Attitudes toward smallpox vaccination}

In response to the question, "If you were [medically] eligible for vaccination and were offered smallpox vaccine today, would you choose to be vaccinated?," $61 \%$ of healthcare workers answered "yes" (32\%) or "probably" (29\%), while the remaining 39\% answered "probably not" (11.6\%), "no" (11.6\%), or "don't know" (15.7\%). Attitudes varied by hospital, ranging from $17 \%$ to $82 \%$ of respondents per hospital inclined toward accepting vaccination ( $\mathrm{p}=.0004$, chi-square test on crude data).

In bivariate analyses, one's opinion of the risk of a smallpox attack was strongly associated with willingness or desire to be immunized ( $\mathrm{p}<.0001)$, with $70 \%$ of those perceiving an intermediate-high risk of attack and $66 \%$ of those without an opinion about the risk being inclined toward vaccination, compared to $47 \%$ of those seeing the risk as low (Table 1). Region other than the Northeast, male sex, having children 18 years or younger at home, being very well-informed about the risks and benefits of vaccination, and reading the vaccine information sheet were associated with planning to be vaccinated (but see caveats in footnote to Table 1). Willingness to be vaccinated was not associated with the demographic variables work area, profession, or age. 
Table 2: Healthcare workers' vaccine safety concerns and self-assessed health history

\begin{tabular}{|c|c|c|}
\hline & $\mathrm{n}$ & $\%$ \\
\hline \multicolumn{3}{|l|}{ Topics about which more information desired* } \\
\hline Likelihood and nature of adverse events & 639 & $28 \%$ \\
\hline Risk of a smallpox attack & 328 & $15 \%$ \\
\hline Risks and health problems of transmitting vaccinia & 339 & $15 \%$ \\
\hline Whether experts/respected peers getting vaccinated & 232 & $10 \%$ \\
\hline Length of protection from previous vaccination & 253 & $11 \%$ \\
\hline Facts about smallpox disease & 233 & $10 \%$ \\
\hline Liability and compensation & 159 & $7 \%$ \\
\hline None - no additional information needed & 48 & $2 \%$ \\
\hline Other & 14 & $1 \%$ \\
\hline \multicolumn{3}{|l|}{ Top concern } \\
\hline Risks outweigh benefits & 566 & $53 \%$ \\
\hline Might transmit vaccinia to family or friends & 277 & $26 \%$ \\
\hline Other & 65 & $6 \%$ \\
\hline Might be expected to work with/near smallpox patient & 57 & $5 \%$ \\
\hline Might transmit vaccinia to patients & 52 & $5 \%$ \\
\hline Might have to miss work after vaccination & 39 & $4 \%$ \\
\hline Might have to work extra hours & 21 & $2 \%$ \\
\hline \multicolumn{3}{|l|}{ General type of adverse event most concerned about } \\
\hline More frequent mild to moderate reactions & 207 & $18 \%$ \\
\hline Less frequent moderate to severe reactions & 801 & $70 \%$ \\
\hline Not particularly concerned about adverse reactions & 130 & $11 \%$ \\
\hline \multicolumn{3}{|l|}{ Self-reported history of smallpox vaccination, age $<30$} \\
\hline Yes & 30 & $11 \%$ \\
\hline No & 215 & $78 \%$ \\
\hline Not sure & 32 & $12 \%$ \\
\hline \multicolumn{3}{|l|}{ Self-reported history of smallpox vaccination, age $\geq 30$} \\
\hline Yes & 573 & $65 \%$ \\
\hline No & 198 & $23 \%$ \\
\hline Not sure & 106 & $12 \%$ \\
\hline \multicolumn{3}{|l|}{ Child/children $<$ I year of age at home (a precaution) } \\
\hline Yes & 72 & $6 \%$ \\
\hline No & 1065 & $94 \%$ \\
\hline \multicolumn{3}{|l|}{ With at least I contraindication (of list of 8) } \\
\hline Yes $(\geq 1)$ & 415 & $37 \%$ \\
\hline Not sure $(\geq 1)$ & 84 & $8 \%$ \\
\hline No (none) & 620 & $55 \%$ \\
\hline \multicolumn{3}{|l|}{ Self-reported contraindications $* *$} \\
\hline Household member with history of eczema/atopic dermatitis & $182 \%$ & $16 \%$ \\
\hline History of eczema/atopic dermatitis & 145 & $13 \%$ \\
\hline Pregnancy or attempting to get pregnant & 88 & $8 \%$ \\
\hline Other acute, chronic, or exfoliative skin condition... & 80 & $7 \%$ \\
\hline Household member with other skin condition & 68 & $6 \%$ \\
\hline Immunosuppressed household member & 45 & $4 \%$ \\
\hline Immunosuppression & 19 & $2 \%$ \\
\hline Allergy to vaccine component & 15 & $1 \%$ \\
\hline
\end{tabular}

* Respondents were instructed to choose up to 2 answers; percentages are of total answers chosen. ** Percentages represent (number saying "yes")/(total respondents giving any answer about the respective condition).

In multivariate analyses that adjusted for clustering within hospital, the number of responses per hospital, work area, profession, and age, four variables were associated with willingness to be vaccinated: perceived risk of an attack (odds ratio (OR) for high/intermediate compared to low perceived risk, $3.2(95 \% \mathrm{CI}, 2.4-4.2))$, self-assessed knowledge about smallpox vaccination (OR for very well compared to not at all informed, 2.0 (95\% CI, 1.1-3.7)), self-assessed previous smallpox vaccination status (OR for vaccinated compared to not, 1.5 (95\% CI, 1.0-2.1)), and gender (OR for men, 1.4 (95\% CI, 1.1-2.0)) (Table 3). 
Table 3: Predictors of healthcare workers' self-reported willingness to accept smallpox immunization, results of multivariate analysis

\begin{tabular}{|c|c|c|}
\hline & Odds ratio* $(95 \% \mathrm{Cl})$ & $\mathrm{p}$-value \\
\hline Perceived risk of a smallpox attack in U.S. within 2 years & & $<0.0001$ \\
\hline High/Intermediate & $3.2(2.4,4.2)$ & \\
\hline Low/Next to zero & Ref & \\
\hline Can't guess & $2.7(1.7,4.1)$ & \\
\hline Region & & 0.13 \\
\hline Northeast & Ref & \\
\hline Mid-Atlantic \& Southeast & $1.4(1.0,2.0)$ & \\
\hline Midwest \& West & $1.5(1.0,2.3)$ & \\
\hline Main work area & & 0.16 \\
\hline Emergency Department or ED consult & $1.3(1.0,1.7)$ & \\
\hline Intensive Care Unit or ICU consult & Ref & \\
\hline Other/none specified & $1.4(0.9,2.2)$ & \\
\hline Profession & & 0.76 \\
\hline Physician & Ref & \\
\hline Non-physician clinician & I.I $(0.8,1.6)$ & \\
\hline Other/none specified & $0.9(0.6,1.5)$ & \\
\hline Age & & 0.07 \\
\hline Up to 29 & $1.5(0.9,2.4)$ & \\
\hline $30-39$ & $1.1(0.7,1.6)$ & \\
\hline $40-49$ & $1.0(0.7,1.5)$ & \\
\hline 50 or over & Ref & \\
\hline Gender & & $<0.001$ \\
\hline Female & Ref & \\
\hline Male & I.4 (I.I, 2.0) & \\
\hline Ever vaccinated & & 0.046 \\
\hline Yes & I.5 (I.0, 2.1) & \\
\hline No & Ref & \\
\hline Not sure & I.I $(0.7$, I.7) & \\
\hline Informed & & $<0.001$ \\
\hline Very well & $2.0(1.1,3.7)$ & \\
\hline Fairly well & $1.5(0.9,2.4)$ & \\
\hline Not well & I. $0(0.6,1.7)$ & \\
\hline Not at all & Ref & \\
\hline
\end{tabular}

* adjusted for clustering within hospital and variation in the number of responses per hospital

Region was not associated with attitude toward vaccination in the multivariate analysis.

\section{Projected behavior under hypothetical "post-event" scenarios}

Respondents' interest in vaccination depended to some extent on geographic proximity of a hypothetical future smallpox case. Of those in any doubt about vaccination (i.e. answering anything other than an unqualified "yes" to the question of whether they would get vaccinated "today"), 30\% said they would seek vaccination if a case were laboratory-confirmed overseas; of the remainder who said no, 53\% said they would do so if a case were confirmed in the U.S. a thousand miles away; of the remainder, $70 \%$ said they would seek vaccination if a case were confirmed in their city. Those uninterested in getting vaccinated even if a case occurred in their city amounted to at least $9 \%$ of the starting group (possibly more, as there was some drop-out over the course of the multi-part question).

When asked if they would report to work if they had not been vaccinated recently and had learned that a patient with smallpox had just been admitted to their facility, $32 \%$ of respondents said "yes," while $68 \%$ expressed reservations to varying degrees: $36 \%$ said "yes, but only if I knew I could get vaccinated on arrival," $17 \%$ responded "probably," 5\% said "probably not," and 10\% said "no." Among those answering "probably" and "probably not", the most common contingency mentioned was the measures taken to contain/prevent transmission of the infection, followed by location of the patient relative to oneself. Age was a significant factor in willingness to go to work under these conditions $-20 \%$ of respondents under 30 vs. $35 \%$ of those 30 or older gave an unconditional 
"yes." There were no statistically significant differences among gender or professional strata in this regard.

\section{Discussion}

Our findings may explain why smallpox vaccine uptake has been relatively limited during the first several months of the U.S. national effort - as of May 2003, only 7\% of the target group of 500,000 health care workers had accepted vaccination. In our survey, the most commonly cited concern was the risk vs. benefit of vaccination, followed by the risk of transmitting vaccinia virus. These matched the two most frequently chosen topics about which more information was desired for making the decision, suggesting that the health-related risks of vaccination are paramount considerations for people and ones about which they feel insufficiently informed. (Liability and compensation were not so important to those contemplating vaccination, although these issues may have become more important since then.) Since that time, there have been reports of cardiac problems and deaths shortly after vaccination. On the other side of the balance, the major factor affecting expressed willingness to be immunized was the perceived threat of bioterrorism. Those rating the risk of a bioterrorist attack using smallpox as intermediate or high were more likely to favor vaccination. It seems probable that a heightening of concerns about vaccine adverse events relative to the fear of a bioterrorist attack underlies the currently low acceptance of smallpox vaccination.

There are two likely reasons for the fact that far fewer workers have been vaccinated than the $61 \%$ expressing a general willingness (and even the 32\% stating a clear intention) to get vaccinated in our December 2002 survey. First, well-publicized decisions of some hospitals and large unions of healthcare workers in early 2003 not to participate in the program, together with the subsequent reports of cardiac problems and deaths following vaccination, likely changed the minds of many prospective vaccinees. Second, social desirability bias tends to cause surveys like this one to overestimate acceptance of vaccination [3]. For example, at one study hospital, only 4 of the 28 respondents who said they intended to be vaccinated in our survey actually accepted the vaccine when, shortly thereafter, it was offered.

A limitation of this study was that the group surveyed was not a random sample of the population of interest, which has implications for the generalizability of the results. However, hospitals from several regions of the country were included, and the response rate was high $(>80 \%)$, including in venues where most members of a particular sub-group would have been expected to be present (e.g. staff meetings of ED doctors). Moreover, our results for healthcare workers are similar to those of random-digit- dial telephone surveys of the general public also carried out in $2002[4,5]$, both in the proportions of respondents reporting willingness to be vaccinated and in the perception of risk of a smallpox attack.

We found wide variation among hospitals in both the proportion of staff expressing a willingness to be immunized and the proportion perceiving a threat of bioterrorist attack. Bivariate analyses turned up no pattern with respect to geographic region, size of hospital, or type of hospital (community vs. tertiary care). It is possible that local effects (e.g. in-hospital education programs, opinions of hospital authorities, the rumor mill) are important in healthcare workers' decision-making, at least on this issue.

Knowledge about smallpox vaccination was one of the factors associated with expressed willingness to be vaccinated, but we think it more likely that an intention to get vaccinated leads one to seek more information rather than that greater information leads one to seek vaccination.

Responses about projected behavior under hypothetical scenarios involving a smallpox release are perhaps not reliable, as the level and effect of panic likely cannot be accurately imagined. Nonetheless, it is worth noting that social desirability bias would tend to overestimate the proportion of people willing to put themselves at risk for the common good. Thus, the one-third of respondents who said (without qualification) they would come to work unvaccinated in the event of a smallpox admission is likely an overestimate.

\section{Conclusions}

We conclude that the success of smallpox vaccination efforts will ultimately depend on the relative weight in people's minds of the risk of vaccine adverse events compared with the risk of being exposed to the disease. Although more than half of the group we surveyed thought the likelihood of a bioterrorist smallpox attack was intermediate or high, less than $10 \%$ of the group slated for vaccination has actually accepted it at this time. Unless new information about the threat of a smallpox attack becomes available, perceptions of the vaccine's risks will likely continue to drive the ongoing decisions of healthcare workers about this vaccine.

\section{Competing Interests}

None declared.

\section{Authors' Contributions}

KY developed the questionnaire in collaboration with the other co-authors, oversaw the analysis, and drafted most of the manuscript. TL conceived of, designed, and guided the study and critically contributed to the interpretation 
and writing. VR obtained approval from IRBs, oversaw production and distribution of the questionnaire, designed and cleaned the original databases, and drafted a section of the manuscript. MO performed the statistical analyses and aided in the data interpretation. DS participated in the design, funding, and critical review of the study. DY helped develop the questionnaire and oversaw its deployment in a large hospital, achieving a high level of participation there. RP secured the participation of hospital epidemiologists, oversaw all phases of the study, and critically contributed to the interpretation and writing. All authors read and approved the final manuscript.

\section{Description of Additional data files}

\section{Additional material}

\author{
Additional file 1 \\ 1. Yih Appendix 1.pdf is CDC's 11/20/2002 draft smallpox vaccine infor- \\ mation sheet, which was distributed with the questionnaire. \\ Click here for file \\ [http://www.biomedcentral.com/content/supplementary/1471- \\ 2458-3-20-S1.pdf]

\section{Additional file 2} \\ 2. Yih Appendix 2.pdf is the questionnaire. \\ Click here for file \\ [http://www.biomedcentral.com/content/supplementary/1471- \\ 2458-3-20-S2.pdf]
}

\section{Acknowledgments}

This study was funded through contract 200-95-0957 with the American Association of Health Plans by the Centers for Disease Control and Prevention, and it received in-kind support from the CDC Prevention Epicenters. Ken Kleinman, ScD, provided statistical advice. We gratefully acknowledge the participation of the CDC Prevention Epicenters, the Duke Infection Control Outreach Network, and the following hospitals and individuals: Barnes-Jewish Hospital (David K. Warren, MD), Beth Israel Deaconess Medical Center (Sharon B. Wright, MD, MPH), Brigham and Women's Hospital, Children's Hospital Boston (Donald A. Goldmann, MD), Hunter Holmes McGuire Veterans Administration Medical Center (Michael Climo, MD), Johns Hopkins Hospital and Howard County General Hospital (Trish M. Perl, MD, MSc, Sara E. Cosgrove, MD, MS), Massachusetts General Hospital (David C. Hooper, MD), Memorial Sloan-Kettering Cancer Center (Kent Sepkowitz, MD), Mt. Auburn Hospital (John L. Tully, MD, Kerrie DiRosario, RN, ClC), Newton-Wellesley Hospital (Michael A. Lew, MD), Northwestern Memorial Hospital (Gary A. Noskin, MD), Salem Hospital (Pamela S. Bayne, RN, MS), Union Hospital (M. Joyce Kelliher, RN, BSN, CIC), University of lowa Hospitals and Clinics (Loreen Herwaldt, MD), Community Memorial Healthcenter, Duke University Medical Center (Keith S. Kaye, MD, MPH), Durham Regional Hospital, Piedmont Hospital,
Raleigh Community Hospital, Kaiser Sunnyside Medical Center (John P. Mullooly, PhD).

\section{References}

I. Shadmi H: Medical workers refusing smallpox vaccine $\mathrm{Ha}$ 'aretz [http://www.haaretzdaily.com/hasen/pages/arch/ArchSearchResultsEng.jhtml]. Oct. 25, 2002

2. Breslow NE and Clayton DG: Approximate inference in generalized linear mixed models (in applications and case studies) J Am Stat Assoc 1993, 88:9-25.

3. Fowler FJ Jr: Improving Survey Questions Thousand Oaks, CA, Sage 1995, 28:

4. Lake Snell Perry \& Assoc., Inc: Americans speak out on bioterrorism and U.S. preparedness to address risk 2002[http:// www.RWJF.org/special/changingworld].

5. Blendon RJ, DesRoches CM, Benson JM, Herrmann MJ, Taylor-Clark $\mathrm{K}$ and Weldon $\mathrm{KJ}$ : The public and the smallpox threat $\mathrm{N} \mathrm{Engl} \mathrm{J}$ Med 2003, 348:426-432.

\section{Pre-publication history}

The pre-publication history for this paper can be accessed here:

http://www.biomedcentral.com/1471-2458/3/20/prepub
Publish with Bio Med Central and every scientist can read your work free of charge

"BioMed Central will be the most significant development for disseminating the results of biomedical research in our lifetime. " Sir Paul Nurse, Cancer Research UK

Your research papers will be:

- available free of charge to the entire biomedical community

- peer reviewed and published immediately upon acceptance

- cited in PubMed and archived on PubMed Central

- yours - you keep the copyright
BioMedcentral 